\title{
LA TASA DE EQUIVALENCIA EN TERRENOS DESTINADOS A CENTROS DE ENSEÑANZA
}

336.8.37

por

Alfonso Pérez Moreno

Profesor Agregado de Derecho administrativo

SUMARIO: I. PLANTEAMIENTO.-II. INTERPRETACION DEL ARTICULO 520, 1, d), DE LA LEY DE REGIMEN LOCAL. LOS CONCEP. TOS JURIDICOS INDETERMINADOS EN LAS NORMAS QUE ESTABLECEN EXENCIONES. - III. ALCANCE DEL ACUERDO MUNICIPAL DE RECONOCIMIENTO DE LA EXENCION.-IV. LA NUEVA FORMULACION DE LA EXENCION EN LA LEY DE BASES DEL ESTATUTO DE REGIMEN LOCAL.

\section{PLANTEAMIENTO}

La complejidad de circunstancias políticas, económicas, sociológicas y técnicas que han determinado el cambio profundo de relaciones entre la sociedad y el Estado y sus Administraciones públicas, se ha dejado sentir vivamente en el campo de la satisfacción de las necesidades públicas, y entre las primeras de ellas está la enseñanza. La menesterosidad social se ha agudizado en este servicio tan enérgicamente que, no sólo ya la legislación ha desplegado un cúmulo de medidas de fomento (como declaraciones de interés social, beneficios económicos y fiscales, subvenciones, etc.), sino que incluso ha declarado la actividad de enseñanza —en la que la colaboración social es, hoy por hoy, ineludible-como un servicio público fundamental (artículo 3,1 de la Ley General de Educación y Financiamiento de la Reforma Educativa, de 4 de agosto de 1970); de tal manera que cualquier institución que tiene en funcionamiento un Colegio, lejos de estar yuxtapuesta o desconectada del Estado, se ha convertido en gestora de un servicio público de primerísimo orden, por lo cual —en espera del advenimiento de más poderosos medios financieros, dentro del calendario de ejecución 
de dicha Ley- la legislación insiste en la introducción de las más favorables medidas de ayuda y fomento que vienen a unirse a las tradicionales - pues la importancia de la enseñanza las ha determinado en todas épocas-; y entre esas medidas están las exenciones y bonificaciones fiscales. Si el desarrollo económico, la industrialización, la construcción de viviendas, la exportación, el deporte, etc., se están viendo favorecidos por, al menos, ese trato fiscal, mucho más han de serlo los Colegios y Centros de educación, que constituyen la base misma del desarrollo económico, social y humano del país. La colaboración fiscal está, además, urgida desde el momento en que nuestro Derecho ha superado ya la vieja idea liberal de concebir el sistema tributario como un simple medio de recaudar dinero. Así, el artículo 4 de la Ley General Tributaria -aplicable también a las Haciendas locales-, dispone: «Los tributos, además de ser medios para recaudar ingresos públicos, han de servir como instrumentos de la política económica general, atender a las exigencias de estabilidad y progresos sociales y procurar una mejor distribución de la renta nacional».

Bajo la inspiración de estos principios, en el panorama fiscal español difícil es encontrar tributos que gravan los bienes o actividades directamente destinados a la enseñanza: la regla general es la exención o la bonificación. Así ocurre en la Contribución Rústica y Pecuaria (artículo 24), Contribución Urbana (artículo 38), Impuesto sobre Rentas del Capital (artículo 53), Impuesto Industrial (artículos 10 y 25), Impuesto de Sociedades (artículo 10), Impuesto sobre Tráfico de Empresas (artículo 212), Impuesto sobre Transmisiones Patrimoniales (artículo 65), Impuesto sobre Bienes de las Personas Jurídicas (artículo 136), Arbitrio sobre Solares edificados y sin edificar (Ley de Régimen local, artículo 590), Arbitrio sobre la Riqueza Urbana (artículo 14). Asimismo está establecida la exención en el Arbitrio sobre el Incremento del Valor de los terrenos (Tasa de Equivalencia), en el artículo 520, d), de la aún vigente Ley de Régimen local. Sin embargo, en torno a este precepto se ha producido una viva polémica que ha venido zanjando el Tribunal Supremo mediante una jurisprudencia de efectos regresivos, que no sólo chocan contra el conjunto del sistema tributario sobre los terrenos destinados a Centros de enseñanza, sino que puede inducir a confusiones, señaladamente entre discrecionalidad y conceptos $j u$ rídicos indeterminados.

La circunstancia de que muchos de los Centros de enseñanza 
pertenezcan a comunidades religiosas, y que se haya tenido en cuenta sólo el artículo XX del Concordato, en relación con el apartado i) del artículo 520 de la Ley de Régimen local, así como la no siempre bien matizada distinción entre destino gratuito del suelo y retribución de la actividad de enseñanza, han derivado en una interpretación limitadora del artículo $520, \mathrm{~d}$ ), que le ha privado de la potencialidad favorecedora que, sin duda, quiso imprimirle el legislador, y que en la actualidad debe ser desarrollada hasta el máximo dadas las graves circunstancias económicas por que atraviesan la casi totalidad de los Centros de enseñanza, que soportan altos déficit.

Las sentencias del Tribunal Supremo más representativas al respecto, son las de 15 de mayo de 1972, 5 de junio de 1972 (que llega a condenar en costas a la recurrente por su temeridad que «resulta aún más evidenciada en esta segunda instancia, por ejercitarse pretensiones contrarias a normas claras e inequívocas, cuya aplicación jurisprudencial ha sido también uniforme y coherente»), 8 de octubre de 1973, 28 de febrero de 1974 y 12 de junio de 1974.

Con independencia del casuismo en que, naturalmente, se concretan dichas sentencias, se viene derivando de ellas en la gestión tributaria municipal una consecuencia desproporcionada, en cuanto, sin fundamento, se generaliza la idea de negación al reconocimiento de la exención establecida concretamente en el apartado d) del artículo 520 de la Ley de Régimen local. Es por ello necesario adentrarse en una interpretación de este precepto.

\section{INTERPRETACION DEL ARTICULO 520, 1, d), DE LA LEY DE REGIMEN LOCAL. LOS CONCEPTOS JURIDICOS INDETERMINADOS EN LAS NORMAS QUE ESTABLECEN EXENCIONES}

El texto articulado de la Ley reformadora del título preliminar del Código Civil de mayo de 1974, que por vez primera en nuestro Derecho positiviza en normas los criterios de interpretación de las leyes, ha introducido el artículo $3 .^{\circ}, 1$, con el siguiente contenido: aLas normas se interpretarán según el sentido propio de sus palabras, en relación con el contexto, los antecedentes históricos y legislativos, y la realidad social del tiempo en que han de ser aplicadas, atendiendo fundamentalmente al espíritu y finalidad de aquéllas». No puede excepcionarse el alcance de esta norma cuanto 
se trata de interpretar preceptos fiscales, pues, a más de ser la ley posterior y última promulgada sobre la interpretación de las leyes en general, no está en modo alguno en contradicción con el artículo 23 de la Ley General Tributaria, que manda que las normas tributarias se interpreten con arreglo a los criterios admitidos en Derecho; y que sus términos se entenderán conforme a su sentido jurídico, técnico o usual, según proceda. Por consiguiente, la interpretación espiritualista y finalista de la norma fiscal es un mandato general de nuestro Ordenamiento jurídico, que ni siquiera viene contradicho por la regla que prohíbe la analogía en materia de hecho imponible, exenciones o bonificaciones, pues cosa bien distinta es la aplicación analógica de la serena, normal y plena interpretación de la propia norma en función de la concreta realidad que constituye su supuesto de hecho.

Recordados estos categóricos criterios sobre la interpretación de las normas, hemos de adentrarnos en el análisis del reiterado párrafo d) del artículo 520 de la Ley de Régimen local.

¿Con qué carácter reconoce la exención del arbitrio en cuestión de los terrenos afectos de un modo permanente a servicios de enseñanza? ¿Tiene dicha exención carácter automático, o es discrecional del Ayuntamiento su otorgamiento? No puede afirmarse que la exención tenga carácter automático, pues no basta que una entidad destine terrenos propios de modo permanente a servicios de enseñanza. Pero tampoco puede afirmarse que el otorgamiento de la exención sea una potestad discrecional del Ayuntamiento, porque la discrecionalidad sería contradictoria con la plenitud y rigor del principio de legalidad en la materia fiscal; el artículo 10, b), de la Ley General Tributaria exige que se regule en todo caso por ley «el establecimiento, supresión y prórroga de las exenciones, reducciones y demás bonificaciones tributarias"; hasta el extremo de que para que el Gobierno pudiera decidir en dicha materia tuvo que ser expresamente habilitado (artículo 20 del Decreto-ley de 27 de noviembre de 1967). No se coordina, pues, bien la fijeza legal que requiere el tema de las exenciones con la idea de que sea discrecional de un Ayuntamiento el que una exención pueda existir. Ciertamente el artículo 520, d), que analizamos prevé una intervención del Ayuntamiento, precisa que debe producirse un acuerdo municipal; pero, por lo expuesto, dicho acuerdo no puede tener el efecto de dar nacimiento a la exención como fruto de una voluntad administrativa. ¿Para qué entonces el necesario acuerdo municipal? Para dar 
determinación a un concepto jurídico indeterminado, es decir, para calificar una realidad fáctica en la que deben concurrir ciertas características a fin de merecer la exención ya directamente reconocida y establecida por la ley; en definitiva, para fiscalizar con garantía unos hechos objetivamente, sea cual sea la voluntad municipal al respecto. Existe, por tanto; una acusada diferencia entre la discrecionalidad, en virtud de la cual el legislador confía a la voluntad administrativa la decisión de un asunto según sea coyunturalmente más conforme con el interés público, y el concepto jurídico indeterminado, en el cual se trata simplemente de constatar unos hechos, unas circunstancias reales, sin añadir ni quitar, subjetivamente, nada a ellos. Por eso, mientras que en la discrecionalidad no es posible que ningún Tribunal sustituya la voluntad administrativa libremente formada, salvo que se compruebe que incurrió la Administración en desviación de poder, desembocando en una arbitrariedad lesiva del interés público, en cambio, en los conceptos jurídicos indeterminados, la inactividad o el error de apreciación de la Administración pueden ser rectificados y sustituidos por los Tribunales apreciando y controlando los hechos. Aplicando esta doctrina a nuestro tema, es evidente que el legislador, en el artículo 520, d), de la Ley de Régimen local otorga la exención a las Entidades por los terrenos propios que afecte de modo permanente a un servicio de enseñanza, pero confía la comprobación de esos hechos a los Ayuntamientos a fin de que constaten la efectiva destinación permanente de los bienes a auténticos servicios de enseñanza. Las circunstancias reales controlables son, pues, una permanente destinación de bienes al fin previsto, de forma unívoca e integral, sin detracción alguna para otros usos o actividades sociales o productivas que no deben merecer el favor fiscal; que se trate de un servicio de enseñanza, de tal manera que el terreno sea directo soporte del mismo, sin intermediación alguna, y que reuna las notas propias de un servicio social en dicho campo, lo que implica una aportación desinteresada del bien, que, en cuanto afecto a tal destino, no produce rentabilidad o beneficio; y sin que sea excepción a ello el hecho de que por la actividad docente, por la remuneración del profesorado y atendimiento de las cargas de la enseñanza se perciban unos ingresos, pues bien se comprende que con ello sólo se trata de conseguir una autofinanciación de la actividad y no una rentabilidad por el destino a ella del terreno. Este conjunto de circunstancias objetivas tan variables es el que está 
obligado a valorar el Ayuntamiento para que adquiera eficacia en cada caso la exención que directamente otorga la ley. Resultado de esta labor de constatación y apreciación será un acuerdo municipal, negativo o positivo, pero en todo caso fiscalizable por los Tribunales, que a la vista de las pruebas y alegaciones expuestas por los interesados ratificará o rectificará la apreciación administrativa.

Las ideas expuestas han tenido ya acogida en la jurisprudencia de la Sala de lo Contencioso-Administrativo de Sevilla y del Tribunal Supremo; y las ha aplicado en relación con un tributo mucho más controvertido y donde la legislación sitúa en un plano decisor más radical a la voluntad municipal. Nos referimos a las tasas por licencia de obras para la construcción de un Colegio mediante un legado para favorecer a la población escolar de un Municipio. El caso es límite, porque sabido es que la tasa supone la contraprestación por una concreta prestación municipal, a diferencia del arbitrio, en el que no se satisface servicio municipal específico. El artículo 438 de la Ley de Régimen local dice que los Ayuntamientos "podrán" otorgar la exención de la tasa cuando el servicio público afecte a las clases productoras de escasa capacidad económica y el interés público en la extensión del servicio lo justifique. El verbo "podrá" está más cerca del otorgamiento de discrecionalidad, y es interesante subrayar que no lo emplea el artículo 520, d), de ningún modo. Negada en aquel caso la exención de la tasa, porque, aún comprendiendo el Ayuntamiento que el Colegio satisfacía una urgente necesidad social, el estado deficitario de su Hacienda no le permitía otorgar la exención, la Sala de lo Contencioso-Administrativo de Sevilla, en sentencia de 27 de mayo de 1968 (recurso número 171/1967) estimó el recurso sobre la base de la siguiente doctrina:

Considerando: Que si el Ordenamiento, con palabras muy sugerentes de la Exposición de Motivos de nuestra Ley Jurisdiccional de 1956, no se encierra y circunscribe a las disposiciones escritas, sino que se extiende a los principios y a la normatividad inmanente en la naturaleza de las instituciones, ello nos permite una visión panorámica del sistema fiscal patrio y, dentro de él, del de las Haciendas locales, agrupado alrededor de unas ideas y unos principios básicos; pues bien: uno de estos principios es el de erradicación de toda discrecionalidad en gestión de los distintos tributos; principio universal y característico de todo Estado de Derecho, pues, como es bien sabido, la materia que más ha contribuido a la constitución de Cuerpos legislativos, representativos de la sociedad, ha sido la tributaria; así pues, sólo la mención 
del concepto de discrecionalidad, dentro del campo fiscal, constituye algo disonante y extraño al sistema, todo él montado sobre el mecanismo de la legalidad, esto es, sobre la existencia de unas reglas previamente dadas, encaminadas fundamentalmente a impedir que los órganos gestores del Fisco puedan disponer de una libertad de acción frente al contribuyente francamente peligrosa; en virtud de lo expuesto, las discriminaciones posibles quedan reservadas al legislador $\mathbf{y}$, por delegación de éste, en este ámbito de las Haciendas locales, a las respectivas Corporaciones, a través del acto creador del tributo, $\mathbf{y}$, sobre todo, del ordenador del mismo, aunque siempre, como es natural, con facultades muy cercenadas, en comparación con las disponibles por quien ostente el poder soberano estatal; éste, sobre todo, en estos tiempos en que el concepto de Hacienda neutral se halla completamente superado, puede imprimir a la imposición una orientación política determinada, progresiva o regresiva, plasmada en normas, pero, con uno u otro sentido, los órganos gestores no son continuadores de este poder político, sino meros aplicadores del Ordenamiento jurídico fiscal; ante ellos, sólo existen actos sujetos o no sujetos, y los primeros, a su vez, exentos o no exentos, y éstos, por su parte, bonificados o no bonificados; lo inconcebible, en un sistema moderno de Derecho, es que, ante un supuesto de hecho perfectamente determinado y tipificado, al órgano gestor le quepa la opción de una conceptuación, con la antagónica (exención o no exención, en nuestro caso) en uso de una discrecionalidad incompatible con el sistema mismo.

Considerando: Que podría pensarse que las ideas expuestas se ven desmentidas en la propia Ley de Régimen local vigente, al permitir, concretamente en sus artículos 438 y 446, una exención del pago de derechos y tasas, por prestación de servicios o aprovechamientos especiales, total o parcial, si los obligados al pago pertenecen "a las clases productoras de escasa capacidad económican, o cuando ello constituya "medio de vida para las clases de menor capacidad económica», mas lo previsto en estos artículos no admite equiparación con la forma en que el Ayuntamiento de $X$ trata de interpretar el precepto do la Ordenanza a que nos venimos refiriendo; en efecto, en tales artículos lo que se contiene es un concepto jurídico indeterminado: "clases de menor capacidad económica», o de "escasa capacidad económica», necesitado de determinación o concreción; por ello, al intérprete sólo le queda la misión, en su labor de subsunción del supuesto de hecho en la norma aplicable, que especificar en el caso concreto si el sujeto pasivo del tributo pertenece o no a esa clase económica, como cuestión de puro hecho, sin el menor atisbo de discrecionalidad, lo que permite a los Tribunales, en su función revisora, controlar plenamente, a través de la prueba sobre esa situación de hecho, el acto liquidatorio de la Administración municipal, pues una cosa es que no se cuente, para la fijación del concepto a que nos venimos refiriendo, con un punto de referencia exacto y matemático, y otra bien distinta que esta dificultad, de puro hecho, signifique que ello es motivo de discreciona- 
lidad en el obrar de la Administración, puesto que la discrecionalidad no se basa ni depende de las dificultades existentes para la aplicación de una norma, lo que es un hecho a posteriori, sino de que, a priori, el legislador haya conferido al funcionario o autoridad poderes de configuración del acto, a base, principalmente, del ejercicio de opciones y alternativas, en función de lo oportuno y conveniente en cada situación, cuando la situación, ¡claro está!, pertenezca a una materia en que todo ello sea posible.

Considerando: Que si, como hemos visto, lo normado en dichos artículos 438 y 446 no representa el menor atisbo de discrecionalidad, ni ha sido propósito de los autores de la Ley conferir poderes discrecionales para la aplicación de los mismos, con mucha más razón no debe pensarse en la discrecionalidad cuando la exención establecida en la Ordenanza de que se trata tiene por destinatarios a unos sujetos perfectamente delineados e identificables, sometidos a un régimen juridico especial y a unas formas preestablecidas, condicionantes de su nacimiento válido en el mundo jurídico; por tanto, la única discrecionalidad, mejor dicho, lo único admisible, en el momento de interpretar la locución de la Ordenanza en cuestión: "El Excelentísimo Ayuntamiento ... podrá declarar exentas del pago...», es que dicha Corporación tenga las facultades para examinar la clase y naturaleza del establecimiento de beneficencia de que se trate, al solo efecto de comprobar si reúne las condiciones exigidas en el Ordenamiento para ser considerado como tal, para evitar que la exención se extienda, indebidamente, a entidades no válidamente constituidas, o en que el fin benéfico sólo sea aparente o simulado.

El Ayuntamiento interpuso recurso de apelación, y el Tribunal Supremo en sentencia de 10 de marzo de 1969 (Ar. 1.262) confirmó la de la Sala de Sevilla, haciendo el siguiente razonamiento:

... nunca es permitido, y menos en el terreno del Derecho, y más aún hoy en el del Derecho Administrativo, en donde la barrera de la discrecionalidad - antes intangible - ha quedado ya jurisdiccionalmente salvada, al admitirse en la Ley vigente de nuestra Jurisdicción los recursos incluso contra actos discrecionales, nunca es permitido -decimos- confundir lo discrecional con lo arbitrario, pues que aquello se halla o debe hallarse cubierto por motivaciones suficientes, discutibles o no, pero considerables, en todo caso, y no meramente de una calidad que las haga inatacables, mientras que lo segundo o no tiene motivación respetable, sino pura y simplemente la conocida sit pro ratione voluntas, o la que ofrece lo es tal que, escudriñando su entraña, denota, a poco esfuerzo de contrastación, su carácter de realmente indefendible, su inautenticidad.

Si este es el juicio de los Tribunales en el caso de una tasa que paga un servicio, y donde la ley deja, con su "podrá», más libertad 
de decisión a los Ayuntamientos, ¿cuánto más tendrían que decir en el caso del arbitrio que discutimos en el que la exención se otorga directamente, el acuerdo municipal es sólo de cautelar constatación y no hay específico servicio municipal que con él se pague?

\section{ALCANCE DEL ACUERDO MUNICIPAL DE RECONOCIMIENTO DE LA EXENCION}

Dicho acuerdo debe ser dictado, sobre todo cuando se pide al Ayuntamiento que lo dicte. No basta el silencio administrativo, ni la inexpresividad en la Ordenanza, para inducir que la exención no existe, pues la existencia de ella no depende de la voluntad municipal, según razonamos. El Ayuntamiento puede y debe tomar el acuerdo de si unos u otros terrenos destinados a servicio de enseñanza están o no en las circunstancias adecuadas para que sea respecto a ellos operativa la exención. No hacerlo equivale a derogar por vía de desuso provocado una exención; o a infringir el principio de inderogabilidad singular de los reglamentos (legem patere quam feciste, artículo 30 de la Ley de Régimen Jurídico de la Administración del Estado).

Así lo han venido ya haciendo algunos Ayuntamientos españoles, y algunos en otras épocas mucho menos angustiosas para la pervivencia de los Colegios. No obsta al reconocimiento de la exención en acuerdo municipal la circunstancia de que el artículo 520, d), diga que debe constar taxativamente en la Ordenanza, y en ésta no conste. Y no obsta, decimos, porque el artículo 523 de la Ley de Régimen local permite, a sensu contrario, que por acuerdo especial pueden reconocer los Ayuntamientos las exenciones previstas en los anteriores artículos (entre los que está el 520, d). El silencio de la Ordenanza, que sólo reitera este precepto pero no hace uso de él, es prueba evidente de que la Ordenanza infringe dicha norma legal de exención, a consecuencia del vicio denunciado de haber convertido el Ayuntamiento en potestad discrecional lo que es concepto jurídico indeterminado, y que debió determinar. La laguna de la Ordenanza puede, pues, interpretarse en uno de estos dos sentidos:

a) O que el Ayuntamiento se reserva constatar los casos de exención mediante acuerdos especiales al amparo del artículo 523 de la Ley de Régimen local. 
b) $\mathrm{O}$ que cree que la laguna debe interpretarse como negativa municipal a aplicar el artículo 520, d); pero en este caso la Ordenanza incurre en infracción, porque contradice la Ley, ya que suprime la exención reconocida sin plantearse ni siquiera que pueda existir un centro de enseñanza merecedor de ella. Para alumbrar el acuerdo municipal deberá el Ayuntamiento tener en cuenta circunstancias generales junto a las específicas que le pruebe cada centro interesado.

Entre las primeras, la más destacable es la angustiosa situación económica de los Colegios, que están soportando un servicio público fundamental, adaptándose a los requisitos señalados por el Estado, entre ellos la intervención en los precios, con la particularidad de que los aumentos autorizados están por debajo de los aumentos que en la remuneración del profesorado se introducen por convenio colectivo. De esta manera, la actividad no se autofinancia y arrastra déficit, teniendo en cuenta por otro lado, por supuesto, que nada se contabiliza por el suelo, ni por concepto de amortización.

\section{LA NUEVA FORMULACION DE LA EXENCION EN LA LEY DE BASES DEL ESTATUTO DE REGIMEN LOCAL}

La base 27 de esta Ley, de 19 de noviembre de 1975, ha venido a disipar las dudas que pudieran derivarse del sistema anterior, disponiendo categóricamente para el Impuesto municipal sobre el incremento del valor de los terrenos que ya no es necesario el acuerdo constatatorio de los Ayuntamientos para que los Centros de enseñanza estén exentos del pago del tributo, sin perjuicio de que queden sometidos los terrenos al impuesto cuando se produzca la transmisión de la propiedad: «En todo caso - dispone- quedarán exentos del pago del impuesto en la mencionada modalidad los terrenos destinados a Centros de enseñanza reconocidos y autorizados por el Ministerio de Educación y Ciencia, sin perjuicio de que queden sometidos al presente impuesto cuando se produzca la transmisión de la propiedad».

En tanto no se dicte el texto articulado, es de suma importancia que tanto la Administración como los Tribunales extraigan del artículo 520, d), de la Ley de Régimen local todas las consecuencias favorables para los Centros de enseñanza que, según se acredita con el análisis del sistema tributario, ha querido otorgarles el legislador. 


\section{RESEÑA DE SENTENCIAS}

SUMARIO: I. ABASTECIMIENTO: CARNES FORANEAS PROCEDENTES DE MATADEROS FRIGORfFICOS.-II. BIENES: 1. CAMINO: DEFENSA POR LA ADMINISTRACIÓN. 2. ENAJENACIÓN: AUTORIZACIÓN Y MERO CONOCIMIENTO del Ministerio de la Gobernación. 3. Deslinde administrativo: ReCUPERACIÓN POR LA ADMINISTRACIÓN. 4. RECUPERACIÓN ADMINISTRATIVA. III. COMPAÑIA TELEFONICA NACIONAL DE ESPANA: CABINAS EN LA VIA PÚBliCA: COMPETENCIA AL EFECTO. - IV. CONTRATACION ADMINISTRATIVA: DEFECTOS DEL CONTRATO: INCOMPETENCIA DE LA CoMisión Permanente.-V: EXPROPIACION FORZOSA: 1. INDEMNIZACIÓN POR DIVISIÓN DE FINCA: IMPROCEDENCIA DEL 5 POR 100 DE AFECCIÓN. 2. JUSTIPRECIO: MOMENTO AL QUE HA DE REFERIRSE.-VI. FUNCIONARIOS: 1. ACTUALIZACION DE PENSIONES: QUINQUENIOS. 2. ACTUALIZACION: VIUDEDAD. 3. CONDICIÓN DE FUNCIONARIO. 4. FUNCIONARIOS DEL MOVimiento. 5. Jubilación: CÓMPUTO dE SERVICIOS INTERINOS. 6. M. U. N. P. A. L.: PROCEDIMIENTO PARA IMPUGNAR SUS ACUERDOS. 7. Pension: cómputo de Quinguenios. 8. Pensión de orfandad oue no SE actualiza. 9. Reingreso de depurado polftico. 10. Secretarios, INTERVENTORES Y Depositarios: Tabla de Valoración de Méritos en Concursos.-VII. HACIENDAS LOCALES: 1. ARBITRIO DE PLUSVA-

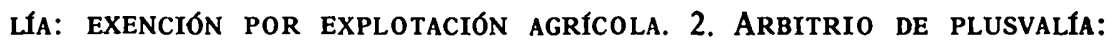

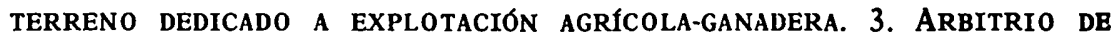
plusvalfa: explotación minera: prueba. 4. Arbitrio de plusvalfa: PRESCRIPCIÓN. 5. CONTRIBUCIONES ESPECIALES: COSTO DE LAS OBRAS: INDEMNIZACIONES A SATISFACER POR EXPROPIACIÓN DE EDIFICIOS Y OTRAS CONSTRUCCIONES. 6. CONTRIBUCIONES ESPECIALES: AUMENTO DE VALOR: EXENCIÓN DE LA RENFE. 7. CONTRIBUCIONES ESPECIALES: COSTO DE EDIFICIOS Y SOLARES DE NECESARIA OCUPACIÓN. 8. CONTRIBUCIONES ESPECIALES: COSTO DE EXPROPIACIONES. 9. DERECH OS Y TASAS: APERTURA DE ZANJaS. 10. Diputaciones ReCaudadoras de contribuciones del Estado. VIII. JURISDICCION CONTENCIOSO-ADMINISTRATIVA: No EXIGENCIA DEL PREVIO PAGO DE EXACCIONES LOCALES PARA ACUDIR A LA VIA CONTENCIOSA. - IX. MONUMENTOS HISTORICO-ARTISTICOS: AUDIENCIA DE LOS INTERESADOS EN EL EXPEDIENTE.-X. POLICIA MUNICiPal: 1. Circulación uRbana: estacionamiento de autobuses de CONCESIONARIO DE SERVICIO REGULAR DE TRANSPORTE POR CARRETERA. 2. LICENCIA DE OBRAS: CONSTRUCCIÓN DE LOCAL COMERCIAL, CON ESCAPARATE, EN EL PORTAL DE ENTRADA A LA CASA. 3. LICENCIA: COMPETENCIA DE la CORPORACIÓN MUNicipal. 4. Licencia: CARÁcter REglado. 5. Licen- 
CIA: SILENCIO ADMINISTRATIVO POSITIVO. 6. LICENCIA: MURO DE CIERRE. 7. RUINA: UNIDAD PREDIAL.-XI. PROCEDIMIENTO ADMINISTRATIVO: Notificaciones: COMPETENCIA del SECRETaRIo de la CorporaCIÓN.-XII. SEGURIDAD SOCIAL AGRARIA: AYUNTAMIENTOS: CUOTA EMPRESARIAL.-XIII. SOLARES E INMUEBLES DE EDIFICACION FORZOSA: TARDANZA DE LA RESOLUCIÓN MUNICIPAL.-XIV. URBANISMO: 1. Licencia erróneamente otorgada. 2. Plan definitivamente APROBADO: RECTIFICACIÓN DEL ACTO ADMINISTRATIVO ALEGANDO ERROR DE HECH O. 3. Planes: MOdificación de los MISMOS: aprobación DEFINITIVA. 4. ORdENACIÓN DE MaNZanas.

\section{ABASTECIMIENTO}

\section{CARNES Foráneas PROCEDENTES DE MATADEROS FRIGoRfFicos}

No cabe reputar infringidos los artículos 19 y 21 del Reglamento de Abastecimiento de Carnes de Madrid, ni es necesaria la presentación de la carne en el Matadero municipal para su inspección sanitaria, cuando se trata de carnes procedentes de mataderos frigoríficos, que fueron debidamente transportadas sin romper la cadena del frío, hasta el depósito de distribución, constituido en el presente caso por Cámaras Frigoríficas "Gredos", y que vienen ya amparadas, con las correspondientes guías sanitarias, sin perjuicio de que en el propio depósito o cámara se ejercite por los Servicios municipales veterinarios la vigilancia o control sanitarios que establece también el párrafo $20^{\circ}$ del artículo 15 del aludido Reglamento de 31 de enero de 1955, en orden a la comprobación de las guías y la condición de los marchamos. (Sentencia de 30 de diciembre de 1975, Ar. 471).

\section{BIENES}

\section{Camino: Defensa por la Administración}

Considerando: Que aunque la autotutela de la defensa posesoria, dentro de lo previsto en los artículos 404 de la Ley de Régimen local y 55 del Reglamento de Bienes, en lo preciso para la pronta satisfacción del interés general claramente perceptible en la gestión frente a invasiones, restricciones o perturbaciones de las vías urbanas o de las vías rústicas, debe recibir, en este orden jurisdiccional, un pleno reconocimiento, pues la merma de esta autotutela y la remisión a la decisión del Juez ordinario podría dañar al uso general, impedido, perturbado o limitado en tanto no se decidiera el litigio, necesitado de un tiempo, ha de mantenerse esta autotutela, sustitutiva, en realidad, de lo que en otros órdenes es actividad propia del Juez, a través del in- 
terdicto judicial, dentro de unas exigencias que eviten extralimitaciones o invasiones de la función jurisdiccional ordinaria, limitaciones que jugarán cuando la cuestión encierra no un tema de clara defensa del uso público que demanda una pronta y eficaz actuación del poder municipal en defensa de un elemento de la red viaria rústica abierto al público, sino el de la naturaleza y titularidad, y el de la misma subsistencia de un camino, si es que en tiempos tuvo el carácter de público, en alguna de las modalidades, y la cuestión se presenta, como aquí ha ocurrido, con destacado matiz de controversia privada entre colindantes en la que la Administración municipal a impulso de uno de ellos y en actuación contradictoria ha dilucidado la cuestión; aspectos de dudosa titularidad y de improbado uso general que, en modo alguno, tienen una respuesta en la sola afirmación de dos testigos, y que, por ello, no debieron resolverse por la vía de la autotutela, sino por la vía judicial. (Sentencia de 14 de febrero de 1976, Ar. 1.090).

\section{ENAJENACIÓN: AUTORIZACIÓN Y MERO CONOCIMIENTO del Ministerio de la Gobernación}

En cuanto al único requisito sustancial cuya infracción se acusa, el del artículo 189 de la Ley de Régimen local y 95 del Reglamento citado, no puede sin embargo reputarse infringido, puesto que los citados preceptos exigen solamente la autorización previa del Ministerio de la Gobernación cuando el valor de los bienes exceda del 25 por 100 del Presupuesto anual de la Corporación, lo que aqui no ocurría según la tasación pericial, en relación con la certificación municipal, y en consecuencia aquel vicio se habría constreñido al inciso final del apartado 1 del precepto legal citado, donde el control preventivo se limita al conocimiento de oficio (no autorización), puesto que solamente se exige que se dé cuenta a aquel órgano de la enajenación que se proyecte. (Sentencia de 27 de diciembre de 1975, Ar. 328).

\section{DESLinde ADMinistrativo: RECUPERACIÓN POR LA ADMINISTRACIÓN}

Que se incumplió evidentemente la propia esencia o finalidad que entraña todo deslinde, que no es otra que la de situar sobre el terreno la finca en cuestión, fijando con claridad el lindero o linderos discutidos, según establecen de modo genérico los artículos 384 y siguientes del Código civil y 2.061 y siguientes de la Ley de Enjuiciamiento civil, y, de modo específico, el número 2 del ya citado artículo 52 del Reglamento de Bienes, al indicar que "el apeo consistirá en fijar con precisión los linderos de la finca», pues, de no ser así, y si se dejan de concretar tales linderos, mal se podrá dar cumplimiento al artículo 54 del 
mismo texto legal, que ordena que «una vez que el acuerdo de aproba. ción del deslinde fuera firme, se procederá al enajenamiento», es decir, a la concreción física y palpable de las líneas perimetrales señaladas jurídicamente en el expediente; y es que, en realidad, lo que parece haber pretendido el Ayuntamiento con la tramitación del expediente es sólo la recuperación en vía administrativa del inmueble discutido, sin tener en cuenta que, si bien con facultad la autorizan los artículos 101, apartado 2, b), y 404 de la Ley de Régimen local, 344 del Reglamento de Organización y Funcionamiento y 55 del Reglamento de Bienes, para su realización no sólo se han incumplido una serie de requisitos (como sería, por ejemplo, el imprescindible del plazo), sino también que tal posibilidad entraña un auténtico privilegio de los Ayuntamientos en cuanto ellos mismos, de forma unilateral y sin necesidad de acudir al amparo de los Tribunales de Justicia, pueden llevar a cabo el rescate de los bienes que se hallen indebidamente en poder de los particulares, y ante tạl privilegio, según ha determinado en múltiples ocasiones nuestro Tribunal Supremo, es necesario la existencia de una prueba plena y acabada, y por eso, «si hay imprecisión o vaguedad de cuál es el ámbito territorial de la posesión públìca y de los límites a que alcanza ésta y dónde comienza la propiedad privada, la acción recuperatoria municipal excede de su auténtica naturaleza estrictamente posesoria, para convertirse en un acto de definición de propiedad para el cual carece de competencia la Administración municipal», y solamente podrá ésta ejercitar dicha recuperación cuando a través del correspondiente expediente de deslinde, efectuado con las formalidades y garantías legales, se localice de manera definitiva la línea o líneas de separación entre el bien público y la propiedad particular, «dando así posibilidad para establecer y concretar sobre una base de hecho firme el alcance físico de cada uno de los derechos, y ocasión a la persona afectada para defender su derecho ante la jurisdicción competente», que no es otra, como antes decíamos, que la ordinaria - sentencias, entre otras, de 18 de enero de 1967 y 26 de enero de 1970-. (Sentencia de 31 de enero de 1976, Ar. 744).

\section{RECUPERACIÓN ADMINISTRATIVA}

1. Que la cuestión se limita a la legalidad del acuerdo del Ayuntamiento de Requena de 13 de octubre de 1971, que decidió requerir a don Manuel T. C. para que dejase libre el camino denominado «de los Ruices a Casas de Cuadra, Las Monjas y Los Marcos», retirando los obstáculos y señales colocados en el mismo en las inmediaciones de la casa de labor de la finca de aquél, sintética enunciación del acto impugnado que pone de relieve cómo se trata de una resolución encaminada únicamente a la conservación del uso público del citado camino, razón por la cual no será preciso pronunciarse acerca de problema alguno de titularidad dominical, ni siquiera en el aspecto prejudicial po- 
sible para esta Jurisdicción, puesto que se trata del ejercicio de facultades administrativas encaminadas a la recuperación de oficio tal como las configuran los artículos 404 de la Ley de Régimen local, 344 del Reglamento de Organización y Funcionamiento y, muy especialmente, el 55 del Reglamento de Bienes, donde se caracterizan como una actuación directa por la Administración de su propio derecho y que tiene el contenido mismo de la acción interdictal civil o sea el ejercicio de la posesión como hecho o del derecho de posesión, si bien actuado en vía administrativa; de lo cual se deriva fundamentalmente, en los casos como el que aquí es cuestión, en que se trata no de la ocupación por particulares de un camino considerado público, sino de su obstrucción y de una resolución administrativa limitada a ordenar su reapertura, que aquélla tanto pudo dictarse en ejercicio de facultades de recuperación de oficio del dominio público como de otras de conservación del uso común derivadas de las facultades de policía especial sobre aquél, y en ambos casos resultaría suficiente con la demostración de la existencia material del trazado de un camino y el uso del mismo por la comunidad para considerar legítima la actividad administrativa tendente a mantener ese uso, que es, en definitiva, el elemento determinante de la calificación de la vía como bien demanial (artículos 329 y 344 del Código civil, 183 y 184 de la Ley de Régimen local y $2 .^{\circ}$ y $3 .^{\circ}$ del Reglamento de Bienes), incluso a falta de un acto formal de afectación, tal como se desprende del artículo 8. \%, 4, del citado Reglamento. (Sentencia de 22 de enero de 1976, Ar. 567).

\section{COMPAÑIA TELEFONICA NACIONAL DE ESPAÑA}

\section{Cabinas en la vía pública: competencia al efecto}

- Considerando: Que la discrepancia surgida entre las partes litigantes en torno al carácter de precario con que se concede por el Ayuntamiento de Oviedo la autorización para instalación de cabinas telefónicas en la vía pública, debiendo a su requerimiento suprimirse o variarse su emplazamiento por razón de planes, proyectos de urbanización, atenciones de los servicios municipales y ordenación del tráfico, no puede ser interpretada al margen de las facultades que se reconocen a la Compañía Telefónica Nacional por las disposiciones mencionadas anteriormente, pero también es preciso reconocer la competencia urbanística municipal para ordenar lo referente a las vías urbanas por su carácter de bienes de dominio público, conforme a los artículos 334 del Código civil y 183 y 184 de la vigente Ley de Régimen local de 24 de junio de 1955, que definen entre los bienes de uso público municipal, los caminos, plazas, calles y paseos de servicio general cuya conservación y policía sea de competencia del Municipio, carácter que notoriamente concurre en el Campo de San Francisco de dicha capital, por lo que la cláusula discutida no puede entenderse en el sentido de una 
concesión graciosa revocable libremente por el Ayuntamiento, pero sin desconocer la competencia legalmente atribuida al mismo para adoptar los acuerdos municipales que resulten procedentes para el cumplimiento de sus fines urbanísticos, de tráfico y generales, razón por la que no pueden sostenerse los acuerdos recurridos en cuanto desconocen la propia competencia municipal para adoptar los acuerdos que puedan resultar legalmente procedentes, aunque impliquen variación en las instalaciones que ahora se autorizan, doctrina que ya sostuvo esta Sala en supuesto de completa similitud en su sentencia de 16 de enero de 1975, que ahora procede aplicar nuevamente.

Considerando: Que, sin embargo, el reconocimiento de la competencia municipal para sus propios fines urbanísticos no supone desconocimiento de la norma contenida en el Decreto de 13 de mayo de 1954, en cuanto impone para las posibles futuras modificaciones de las instalaciones telefónicas la obligación de abonar el 50 por 100 de los gastos la Compañía Telefónica y el otro 50 por 100 el organismo que solicite la modificación. (Sentencia de 25 de febrero de 1976, Ar. 1.040).

\section{CONTRATACION ADMINISTRATIVA}

\section{DEFECTOS DEL CONTRATO : INCOMPETENCIA DE LA COMISIÓN Permanen'te}

El Ayuntamiento impugna la validez del contrato por los defectos formales que denuncia en su fundamento tercero, donde asegura corresponde al Ayuntamiento en Pleno, como órgano deliberante de la Administración municipal, la contratación de obras y servicios, careciendo de atribuciones la Comisión Permanente, y como el contrato fue firmado por-el Alcalde y dos Tenientes de Alcalde sin aparecer autorizado ni aprobado por el Pleno, es visto que se trata de un contrato defectuoso; pero sin desconocer cuanto hay de verdad formal en sus argumentaciones ni que frente al criterio espiritualista de nuestro Ordenamiento civil, el administrativo se rige por el criterio formalista como garantía expresa de los intereses públicos que la Administración tutela, ni es aceptable que se invoque en propio beneficio un defecto contractual imputable a quien pretende obtener provecho de él, cuando por la puridad de su forma específica debieran vigilar los funcionarios especializados de la Corporación, ni es posible agotar la razón de su débito en la fuente de la obligación de un suministro concertado, aceptado y consumido en la mera génesis contractual, pues, definitivamente, siempre vendría obligado al pago por las razones éticas y de equidad fundamentadoras del principio de enriquecimiento injusto, porque, como estableció la sentencia de 25 de febrero de 1965 , y ratificó la de 24 de junio de 1969, no puede el Ayuntamiento responsabilizar de sus personales omisiones al otro contratante ni enriquecer a su costa su 
patrimonio; correspondiéndole el deber de hacer totalmente realizable las consecuencias del pacto sin perjuicio de quien con ella contrató de buena fe, cumpliendo rigurosamente el acuerdo concertado $y$, sobre todo, realizando las prestaciones a que se obligó que deben ser necesariamente correspondidas con la recíproca de la contraprestación de su abono por un principio de elemental justicia intrínseca. (Sentencia de 20 de noviembre de 1975, Ar. 188).

\section{EXPROPIACION FORZOSA}

1. INDEMNIZACIÓN POR DIVISIÓN DE FINCA: IMPROCEDENCIA DEL 5 POR 100 DE AFECCIÓN

Considerando: Que sobre el justo precio de los bienes expropiados ha de girarse el 5 por 100 en concepto de premio de afección, a tenor del artículo 47 de la Ley de 16 de diciembre de 1954, con el resultado de 113.475,10 pesetas, pero sin aplicarse sobre la cifra de indemnización por perjuicios derivados de la división de la finca, ya que al tratarse de indemnización complementaria no merece el 5 por 100 de afección, según el artículo 47 del Reglamento de la Ley y la doctrina de la Sala expuesta en reiteradas sentencias, entre ellas las citadas anteriormente. (Sentencia de 18 de marzo de 1976, Ar. 1.130).

\section{JUSTIPRECIO: MOMENTO AL QUE HA DE REFERIRSE}

Es correcta la argumentación que contiene el cuarto Considerando de la sentencia, conducente a que lo procedente, dado el indiscutido carácter de solar del terreno, es atender al valor asignado para los efectos del Arbitrio municipal sobre incremento de valor de los terrenos, aumentado en un 10 por 100, como previene el artículo 38 de la Ley de Expropiación, pero aceptando tal criterio tiene que reconocerse que se incurre en error en el Considerando aludido, al aplicar los índices del trienio 67-69, pues aunque dentro de ese plazo se declaró la necesidad de ocupación y efectivamente se ocupó la finca, las actuaciones administrativas acreditan que el expediente de justiprecio se inició el 26 de febrero de 1970, y esta Sala tiene declarado que es a ese momento al que ha de referirse la tasación, como dispone el artículo 36 de la citada Ley, de preferente aplicación a la norma de rango inferior, contenida en el artículo 28 del Reglamento de 26 de abril de 1957, "no sólo por ser ello lo legal, sino por conformarse a lo justo y equitativo, pues, produciéndose un constante aumento en el precio de los terrenos, sería completamente contrario a derecho el referido al remoto tiempo en que fueron ocupados sin pagarse su valorn, según se dice en la sentencia de 10 de marzo de 1967 de esta Sala, que lo tiene también rei- 
terado, entre otras, en la de 13 de marzo de 1969, procediendo por ello, aplicando los índices del trienio $70-72$ acreditados por certificación del Secretario del Ayuntamiento de Zaragoza, incrementados en el 10 por 100, tener cada uno de los 196 metros cuadrados sobre los que se constituye la servidumbre de acueducto en el precio de 2.640 pesetas -en vez de las 2.200 pesetas que por corresponder al trienio anterior se les atribuye en la sentencia apelada-, lo que hace un total de 517.440 pesetas. (Sentencia de 22 de marzo de 1976, Ar. 1.145).

\section{FUNCIONARIOS}

\section{ACtUalización DE PENSIONES: QuiNQUeNios}

Considerando: Que en el presente recurso la cuestión que se plantea es la de si el régimen de quinquenios que hay que aplicar al fijar las pensiones actualizadas en favor de los funcionarios locales y sus familias es, como sostiene la resolución recurrida, el establecido en la Ley 108/63, en virtud de la cual se ha producido la actualización de la pensión de doña Juana B. P., o como sostiene la Mutualidad recurrente, el que estaba vigente en el momento de cesar en el servicio el funcionario causante de la pensión.

Considerando: Que reiterada jurisprudencia de esta Sala, como la contenida en las sentencias citadas en los vistos, tiene declarado que la actualización de las pensiones tiende a evitar la desigualdad de las mismas, motivada por haber cesado los causantes en el servicio activo en fechas diferentes, y para lograr tal finalidad mediante la actualización las pensiones que se fijan serán las que causarían en el momento de practicarla los funcionarios de la misma categoría y circunstancias del causante de la pensión, con lo que se da cumplimiento a la norma segunda del artículo 10 de la Ley 108/63, en la que se dispone que el sueldo regulador que se adoptará «en todo caso», es el que los causantes habrían consolidado en activo con arreglo a la legislación vigente a la sazón, "si los cargos o puestos de trabajo que desempeñaron hubieren estado dotados con los emolumentos que ahora corresponden», doctrina de rigurosa aplicación al presente caso, que conduce a la desestimación del recurso. (Sentencia de 10 de febrero de 1976, Ar. 400).

\section{ACTUALIZACión: VIUDEDAD}

Considerando: Que la recurrente doña Manuela F. F. -en su calidad de viuda del que fue guardia de la Policía Municipal del Ayuntamiento de Madrid don Prudencio V. R., que cesó éste por fallecimiento en el servicio activo el 9 de abril de 1952-, postuló en vía administra- 
tiva que se le aplicase en la actualización de su pensión de viudedad el porcentaje del 45 por 100 y no el estimado por la M. U. N. P. A. L., que fue el del 25 por 100 , por ser éste el que se tuvo en cuenta al otorgársele la pensión originaria; resolución la última que fue confirmada, en alzada, por el Ministerio de la Gobernación en acto administrativo fechado el 28 de abril de 1971; que es precisamente el que constituye el objeto de este recurso jurisdiccional.

Considerando: Que la actualización tiene por objeto buscar la debida ecuación entre el regulador de los preceptores antiguos y el de los de igual categoría y clase y con idénticos servicios que ahora causan pensión; lo que trae como indeclinable consecuencia que no se ha de variar más que dicho regulador, manteniendo por el contrario todos los demás factores determinantes del haber pasivo, y entre ellos el porcentaje que se fijó a la pensión originaria en trance de actualización, que es, precisamente, lo que se deduce del artículo 10 de la Ley 108/ 1963, de 20 de julio, y de la regla segunda de la Orden de 22 de abril de 1964, según dejó recientemente sentado esta Sala en las sentencias de 7 de febrero y 18 de junio de 1975, que recogen criterio anteriormente reiterado. (Sentencia de 6 de marzo de 1976, Ar. 952).

\section{CONDICIÓN DE FUNCIONARIO}

Es principio mantenido en el ámbito del Derecho administrativo que la condición de funcionario - menos el de carrera- no puede adquirirse por usucapión - sentencias de 12 de mayo de 1947, 20 de junio de 1949, 3 de abril de 1952, 3 de octubre de 1953, 11 de mayo de 1961, 7 de diciembre de 1973 y 3 de junio de 1974, entre otras. (Sentencia de 18 de marzo de 1976, Ar. 1.128).

\section{Funcionarios del Movimiento}

Considerando: Que es jurisprudencia reciente de esta Sala - sentencia de 22 de diciembre de 1975, entre otras- que los funcionarios del Movimiento no forman parte de la Administración pública, ni los actos del Ministro-Secretario en materia de esta clase de personal son actos administrativos, y ello en la actual regulación, dimanada del Texto Refundido de las Leyes Fundamentales del Reino de 20 de abril de 1967 y Decreto-ley de 3 de abril de 1970, pues las normas posteriores a las citadas, específicamente reguladoras del Movimiento, como el Estatuto Orgánico de 20 de diciembre de 1968, Decreto-ley de 3 de abril de 1970, Decreto de 26 de mayo de 1970 y Decreto de 21 de agosto de 1970 , continúan calificándolo como una institución política intermedia entre la Sociedad y el Estado e independiente de la Administración, 
con una esfera de actuación propia, dentro de la que se encuadran las materias de su personal, sujeto a un estatuto especial, que no tiene carácter administrativo, por lo que, en consecuencia, los actos adoptados en dicha materia por los órganos correspondientes del Movimiento no son impugnables ante la jurisdicción contencioso-administrativa, procediendo acoger la causa de inadmisibilidad, fundada en el artículo 82, apartado a), en relación con el 37 de la Ley de 27 de diciembre de 1956. (Sentencia de 21 de enero de 1976, Ar. 38).

\section{JUBILACIÓN: CÓMPUTO DE SERVICIOS INTERINOS}

Considerando: Que el tema de fondo se concreta, según las pretensiones de los litigantes, en decidir si la parte de la pensión de jubilación de don José V. J., funcionario del Ayuntamiento de Málaga jubilado forzoso el 30 de noviembre de 1969, correspondiente al tiempo de servicios efectivos prestados con carácter provisional ha de ser a cargo de la Mutualidad Nacional de Previsión de la Administración Local, al igual que la parte correspondiente al tiempo de servicios en propiedad, tesis de la entidad recurrente, Ayuntamiento de Málaga, o lo será a cargo de esta Corporación como decidió la resolución impugnada, y sostienen en sus contestaciones a la demanda el Abogado del Estado y la citada Mutualidad.

Considerando: Que es aplicable al caso litigioso el artículo 4.० del Decreto 3083/1970, de 15 de octubre, dictado conforme a la autorización concedida por el Decreto-ley 23/1969, de 16 de diciembre, cuyo precepto impone a las Corporaciones locales la obligación de abonar las pensiones producidas por hechos posteriores al primero de enero de 1969 respecto a los servicios efectivos de carácter interino, temporal, eventual o cualquier otro no calificado de en propiedad, en cuanto representen aumento de las prestaciones pasivas; y habiéndolo así dispuesto para el actual supuesto comprendido en dicha norma, la resolución recurrida, ésta aparece claramente ajustada al Ordenamiento jurídico, y de contrario no puede aceptarse la tesis actora sobre abono por la Mutualidad de la totalidad de la pensión, pues las disposiciones en que se fundamenta (transitoria segunda de los Estatutos mutuales de 12 de agosto de 1960, Ley 108/1963, de 20 de julio, y Circulares del Ministerio de la Gobernación número 8 de 1961 y de 2 de abril de 1964) no regulan específicamente el supuesto debatido, y además, excepto la Ley 108/63, son de inferior rango legislativo; de donde, concluyendo, se desestima el recurso por imperativo del artículo 83, 1, de la Ley Jurisdiccional. (Sentencia de 23 de enero de 1976, Ar. 75). 
CONSIDERANDO: Que lo expuesto justifica plenamente la juridicidad del precepto reglamentario de que se trata $y$, por tanto, la necesidad de prestarle el debido acatamiento, como así viene sucediendo en la práctica diaria, en la que dicho artículo 81 de los Estatutos de esta Mutualidad se cumple, sin ponerlo en cuestión; por otra parte, como la resolución de la Dirección Técnica de dicha Entidad, de 11 de marzo de 1970, resolviendo el caso «en uso de las facultades delegadas en la misma por la Comisión Permanente del Consejon, contiene las advertencias necesarias con los recursos utilizables, totalmente de acuerdo con lo prevenido en el precepto que acaba de ser citado, es obvio que la accionante, al acudir, per saltum, en alzada, ante el Ministerio de la Gobernación, eludiendo la otra alzada previa ante el Consejo de Administración de la Mutualidad, ha infringido abiertamente el orden procedimental existente, de cumplimiento necesario, para agotar la vía administrativa. (Sentencia de 4 de febrero de 1976, Ar. 347).

\section{PENSIÓN: CómPUTO DE QUINQUENIOS}

Constderando: Que el recurrente, funcionario jubilado, por imposibilidad física, del Ayuntamiento de Morón de la Frontera, a quien al actualizarle la pensión conforme al Decreto 3083/70, de 15 de octubre, se le han computado cuatro quinquenios y un porcentaje sobre el haber regulador del 65 por 100, pretendió de la Administración que se le aumentaran los quinquenios y elevase el porcentaje al 85 por 100 , y contra la desestimación presunta de tales pedimentos entabló el presente recurso contencioso-administrativo. (Sentencia de 11 de febrero de 1976, Ar. 402).

\section{Pensión de orfandad oue no SE actualiza}

ConsIDERANDo: Que se trata de una pensión de orfandad que no se actualiza por la Mutualidad Nacional de Previsión de la Administración Local, por resultar superior la que venía percibiendo con arreglo a los Estatutos del Montepío de Funcionarios del Ayuntamiento de Madrid, y respecto a ella ha de concretarse que con arreglo a la legislación aplicable en la actualidad por ser mayor de veintitrés años la recurrente no le correspondería pensión alguna, por lo que el otorgamiento de la misma se basa exclusivamente en el principio del respeto a los derechos adquiridos recogido en la disposición adicional cuarta de la Ley 11/60, de 12 de mayo, que según declaró esta Sala, entre otras, en sentencias de 6 de junio, 3 de noviembre y 4 de diciembre de 1969, queda 
salvado siempre que no se disminuya la cuantía total de la pensión que hubiera llegado a percibirse con arreglo a la legislación anterior, lo que no sucede en el presente caso, en que tal disminución no se produce, por lo que las resoluciones impugnadas aparecen ajustadas a Derecho, y carecen de fundamento las pretensiones de actualización, aplicando por una parte las condiciones más beneficiosas de la legislación anterior en cuanto a edad y porcentaje y tomando a su vez las correspondientes a grado retributivo y demás emolumentos de la posterior, con lo que se llegaría a una conclusión totalmente contraria a la perseguida por las normas sobre actualización. (Sentencia de 3 de marzo de 1976, Ar. 935).

\section{REINGRESo de DEPURADo Polf́tico}

Considerando: Que la cuestión que en el presente recurso se plantea se reduce a si cabe acordar la depuración y readmisión al servicio activo del recurrente, que fue nombrado Oficial segundo del Ayuntamiento de Vélez de Benaudalla (Granada) en 1923, desempeñando dicho cargo sin interrupción hasta febrero de 1937, fecha en que dicho Municipio fue liberado por las tropas nacionales, a partir de cuyo momento abandonó su cargo de funcionario municipal, ausentándose de la población y no cumpliendo ninguno de los requisitos exigidos por la legislación dictada sobre depuración de funcionarios, permaneciendo en dicha situación más de treinta y tres años, pues hasta el día 6 de agosto de 1970 no solicitó que se acordase su depuración y readmisión, primero al Ayuntamiento y luego al Ministro de la Gobernación.

ConsIDERANDo: Que la legislación sobre depuración de funcionarios públicos constituida por la Ley de 10 de febrero de 1939 y Orden de 12 de marzo del mismo año, en lo que a los funcionarios de la Administración local se refiere, estableció una serie de normas que afectaban esencialmente a la' relación funcionarial, señalándose un plazo dentro del cual los funcionarios habían de presentar una declaración jurada ante la Corporación local que designaba Instructor para comprobar su veracìdad y proponer la admisión del funcionario sin imposición de sanción o la incoación de expediente para imponer la sanción procedente; de no cumplirse estos requisitos se estableció taxativamente en la Orden últimamente citada, el funcionario decaerá de su derecho para solicitar el reingreso, y como el hoy recurrente ha dejado transcurrir más de treinta y tres años antes de presentar la indicada declaración jurada y solicitar el reingreso, sin que haya justificado ninguna causa de fuerza mayor que le impidiera hacerlo en tiempo oportuno, es claro que decayó de su derecho para pedir el reingreso en un cargo que abandonó voluntariamente, por lo que el recurso presentado debe ser desestimado. (Sentencia de 29 de enero de 1976, Ar. 68). 


\section{Secretarios, INTERVEntores y Depositarios: Tabla de Valoración de Méritos en Concursos}

Se trata del recurso interpuesto por el Colegio contra la Orden del Ministerio de la Gobernación de 5 de septiembre de 1973, y que el Tribunal Supremo desestima, excepto en la parte a que se refiere en el siguiente Considerando:

CONSIDERANDo: Que de igual modo se pretende la nulidad parcial de la Orden de 5 de septiembre de 1973 por desajuste jurídico respecto a la norma de superior rango legal que desarrolla, es decir, el Decreto de 26 de julio del mismo año, ya que la citada Orden en el apartado a) del número 10 que agrega a la Tabla de Valoraciones, establece como mérito con tres puntos de valoración, el haber desempeñado durante dos años "cargo relacionado con la Administración local de designación por Decreto», en tanto que el Decreto de 26 de julio señala como mérito el desempeñar servicios extraordinarios a la Administración local por tiempo superior de dos años «en los cargos que se determinen en la Tabla de Valoraciones" y en este extremo sí es forzoso aceptar la tesis de la demanda en primer lugar porque el Decreto exige «servicios extraordinarios a la Administración local en los cargos que se determinen en la Tabla de Valoraciones» y la Tabla sólo el desempeño de cargo relacionado con la Administración local de designación por Decreto, lo que constituye una notable imprecisión que contraría, en materia tan delicada como son los méritos para la resolución de concursos para provisión de vacantes, la indudable finalidad del Decreto de "determinar" dichos cargos, como se efectúa en la Orden en los apartados b) y c) en que se enumeran y especifican, en tanto que con la genérica expresión del apartado a) cabe incluir cargos de designación por Decreto que aun relacionados con la Administración local no constituyan servicios extraordinarios a la misma y en todo caso el concepto de "relacionados» es susceptible de muy diversas interpretaciones y extensiones, quebrando uno de los principios que aconsejan en materia de concursos y méritos la mayor concreción posible, agravada esta imprecisión en el presente caso por el hecho de la alta puntuación asignada a este mérito, lo que si no influye en orden a decidir si la Orden concuerda o se opone al Decreto que desarrolla, llevaría consigo indudablemente una posibilidad de consecuencias altamente perturbadoras para el buen servicio y la selección de los funcionarios, razones todas por las que ha de declararse la nulidad del apartado a) del número 10 de la Orden de 5 de septiembre de 1973 por oponerse al Decreto de 26 de julio del mismo año, que desarrolla, norma de superior rango jurídico a tenor del artículo 23 de la Ley de Régimen Jurídico de la Administración del Estado, Texto refundido de 26 de julio de 1957 (Sentencia de 10 de marzo de 1976, Ar. 922). 


\section{HACIENDAS LOCALES}

\section{ARbitrio de plusvalf́a: eXención POR EXPLOTACión aGRícola}

Que analizado con las perspectivas resultantes del razonamiento precedente el caso de autos, y concretándonos al primero de los puntos, es decir, a si existe o no explotación agrícola, hemos de recordar, como con absoluta reiteración viene manteniendo el Tribunal Supremo en los últimos años, que la existencia de la «explotación agrícola», a los efectos de este Arbitrio, no se demuestra con la simple aportación de los recibos de la Contribución Rústica de Organización Sindical Agraria y otros semejantes, pues lo anterior sólo prueba la existencia de "finca agrícola», mas no de "explotación agraria», por lo que resulta indispensable que se ponga claramente de relieve con carga de prueba por el recurrente que se opone a la efectividad del arbitrio cuáles son específicamente los rendimientos de la finca, qué cuantía alcanzan dichos rendimientos, y qué proporción guardan éstos con el valor de aquéllos, porque «no existe una auténtica explotación agrícola a efectos del Arbitrio, si no se acredita que los rendimientos de la finca gravada guarden la debida proporción con su valor en venta (sentencias de 2 de marzo, 5 de abril, 25 de mayo y 4 y 6 de julio de 1973 y 22 de enero de 1974). (Sentencia de 28 de febrero de 1976, Ar. 851).

\section{Arbitrio de plusvalf́a: terReno dedicado a eXplotación AGRÍCOLA-GANADERA}

No puede considerarse exento un terreno que se dice dedicado a estos fines si los rendimientos no guardan proporción con una explotación de esta clase y si se adquirió para construir sobre el mismo viviendas, pues, como dijo la sentencia de 4 de julio de 1973, "la explotación en la que está pensando la Ley, por los radicales efectos que produce en esta materia, tiene que caracterizarse no sólo por su intensidad y su organización, sino por corresponder a una situación en la que sobre el precio no presionen circunstancias ajenas a la de su actual destino, capaces de influir decisivamente en su valoración» (Sentencia de 2 de febrero de 1976, Ar. 361).

\section{ARbitrio de plusvalfa: explotación minera: PRUeba}

Reiterada doctrina de esta Sala interpreta la excepción contenida en el artículo 510, 1, de la vigente Ley de Régimen local, en el sentido de que se requiere la prueba por parte de quien la alegue de la existencia de una explotación agrícola, forestal, ganadera o minera (Sentencia de 30 de diciembre de 1975, Ar. 206 de 1976). 


\section{ARbitrio de Plusvalía: PRESCRIPCión}

CONSIDERANDo: Que finalmente, y en relación con ambas fincas y liquidaciones por la tasa denominada de plusvalía, se alega la prescripción de la acción fiscal, ya que desde la escritura de compraventa otorgada en 15 de febrero de 1962, habrian transcurrido los cinco años que para tal prescripción señala el artículo 796 de la Ley de Régimen local para los créditos no liquidados, plazo de prescripción concordante con el señalado por el artículo 64, letra a), de la Ley General Tributaria vigente, pero esta alegación de la apelante no puede aceptarse, ya que, según el artículo 66-1 c) de la misma Ley tributaria, los plazos de prescripción se interrumpen, por cualquier actuación del sujeto pasivo conducente al pago o liquidación de la deuda, y por tanto devengado el arbitrio el 15 de febrero de 1962 con el otorgamiento de la escritura de compraventa de las fincas, la presentación en 2 de junio de 1964 de las correspondientes declaraciones juradas por la apelante, determinó la interrupción del plazo quinquenal prescriptorio, ya que tales declaraciones son actos emanados del sujeto pasivo que conducen a la liquidación de la deuda tributaria, por lo que al efectuarse por el Ayuntamiento y ser notificadas en 16 de enero de 1968, no había prescrito la deuda, razón por la que debe desestimarse la apelación también por el fundamento que ahora se examina (Sentencia de 29 de enero de 1976, Ar. 492).

\section{CONTRIBUCIONES ESPECIALES: COSTO DE LAS OBRAS:} INDEMNIZACIONES A SATISFACER POR EXPROPIACION DE EDIFICIOS Y OTRAS CONSTRUCCIONES

Considerando: Que sobre el primero y fundamental problema, planteado en esta apelación - si en la cifra global del costo de las obras a cubrir mediante contribuciones especiales, es lícito incluir el importe de las indemnizaciones que el Ayuntamiento deba satisfacer por expropiación de edificios y otras construcciones- ya se ha pronunciado esta Sala en sus recientes sentencias de 14 de junio y 24 de septiembre de 1975 y 27 de enero de 1976, que resuelven afirmativamente la cuestión en consonancia con la de 10 de octubre de 1973 y las demás que en la primera de las referidas sentencias se citan, sentando, entre otros, como puntos de doctrina - que deben reiterarse ahora-, en primer lugar: que el artículo 117 de la Ley del Suelo sólo es aplicable en el sistema de "cooperación", ajeno al caso del litigio, en que, el seguido es el de "cesión de viales"; y en segundo lugar, que al no corresponder las obras municipales a proyecto alguno de "nueva urbanización parcial», recobran todo su imperio los artículos 131, 144 y 154 de la Ley de Régimen local, que resuelven el problema planteado en los términos en que lo hace la sentencia objeto de esta apelación (Sentencia de 3 de marzo de 1976, Ar. 1.133). 


\section{CoNTRIBUCIONES ESPECIALES: AUMENTO DE VALOR: EXENCIÓN DE LA RENFE}

CONSIDERANDo: Que como se señaló en los considerandos de la sentencia apelada que fueron aceptados por los de la Sala Quinta del Tribunal Supremo de 6 de noviembre de 1971, el patrimonio de la Red Nacional de los Ferrocarriles Españoles a que se refieren los artículos 1, 3 y 28 de su Estatuto aprobado por Decreto de 23 de julio de 1964, es en rigor patrimonio del Estado a quien corresponde su titularidad plena de acuerdo con el artículo 28, y esto, tanto de los bienes que integran en general la red como de aquellos que posteriormente se adquieran para mejorar y completar la explotación del sistema (artículo 26), lo que no los exime de las contribuciones por beneficios especiales, ya que el apartado b) del artículo 472 de la Ley de Régimen local únicamente declara la exención en cuanto a los bienes del Estado que inmediatamente interesen a la defensa nacional, circunstancias que evidentemente no se dan en los que integran el patrimonio de la RENFE, y así lo ha reconocido la jurisprudencia en sentencias de 26 de febrero de 1968, 22 de febrero y 3 de junio de 1971, pero sí de las contribuciones por aumento de valor, por aplicación del apartado a) del artículo 468 de la Ley de Régimen local, como se reconoció en la sentencia citada de 3 de junio de 1971, que establece que por estar los bienes afectados a un fin público y excluidos por tanto del tráfico patrimonial, mientras la desafectación no tenga lugar, no puede producirse el aumento de valor que es presupuesto de estas imposiciones (Sentencia de 20 de febrero de 1976, Ar. 724).

\section{CONTRIBUCIONES ESPECIALES: COSTO DE EDIFICIOS Y SOLARES DE NECESARIA OCUPACIÓN}

Considerando: Que la cuestión que con carácter primordial plantea en esta apelación el Abogado del Estado se reduce a determinar si en el concepto de coste global de las obras cuyo montante ha de distribuirse, en la proporción legal, entre los vecinos beneficiados con las mismas mediante el procedimiento de contribuciones especiales, debe incluirse o no el importe total de las indemnizaciones abonadas por las construcciones y solares expropiados por el Ayuntamiento de Vigo y que han de ser ocupados para la ejecución de aquellas obras que conciernen al proyecto de apertura y urbanización de la calle que desde Sanjurjo Badía llega a la Sección Delegada de La Guía.

Considerando: Que la expresada cuestión no ha sido ya resuelta en sentido afirmativo por la más reciente jurisprudencia de esta Sala -sentencias, entre otras, de 14 de junio, 24 de septiembre y dos de 5 de 
diciembre de 1975, 15 y 27 de enero del año en curso-, que al respecto sienta los siguientes puntos de doctrina: primero, que el artículo 117 de la Ley de Régimen del Suelo y Ordenación Urbana de 12 de mayo de 1966 solamente es aplicable en el sistema de cooperación, ajeno al caso del litigio, en que el seguido es el de cesión de viales; y segundo, que al no corresponder las obras municipales a proyecto alguno de nueva urbanización, sino a obras de urbanización parcial, es de específica referencia el sistema ordinario o normal de los artículos 131, 143, 144 y 154 de la Ley de Régimen local, Texto de 24 de junio de 1955, que resuelven el problema planteado en los mismos términos en que lo hace la sentencia objeto de este recurso; añadiendo, por otra parte, aquellas resoluciones de este Tribunal que no existe ninguna razón, económica ni jurídica, para excluir de la aportación particular, no mediando precepto legal que así lo disponga, capítulos sin los cuales la realización de la obra no puede concebirse (Sentencia de 20 de febrero de 1976, Ar. 720 ).

\section{CoNTRIBUCIONES ESPECIALES: COSTO DE EXPROPIACIONES}

Considerando: Que la única cuestión que plantea la apelación entablada por el Abogado del Estado, contra la sentencia dictada por la Sala de lo Contencioso-Administrativo de la Audiencia Territorial de La Coruña, con fecha 3 de octubre de 1974, en el pleito número 266 de dicho año, es la relativa a la determinación del coste de las obras realizadas por el Ayuntamiento de Vigo, que se van a cubrir en parte mediante la imposición de contribuciones especiales, cuestión que ha sido reiteradamente resuelta por esta Sala, en sus sentencias de 14 de junio, 24 de septiembre y 5 de diciembre (dos sentencias) de 1975, en el sentido de que el importe de las expropiaciones para la apertura de nuevas calles, es un concepto comprendido en el artículo 454-1-b) de la Ley de Régimen local, que se refiere al valor de los terrenos que las obras o instalaciones hubiesen de ocupar permanentemente, aunque pertenezcan al Ayuntamiento, siempre que no fueran con anterioridad de uso público; y ello es así, porque si el Ayuntamiento está facultado para incluir en el presupuesto sus propios terrenos, para la aportación de los cuales no tiene que realizar desembolso alguno, con mayor razón ha de poder cargar el valor de los terrenos que se afecten permanentemente a las obras o instalaciones, cuando se trate de una aportación onerosa, a través de la correspondiente expropiación; sin que la anterior conclusión, que surge de un precepto específico de la Ley de Régimen local, pierde validez a consecuencia de la Ley del Suelo, cuando no consta que se haya seguido el sistema de compensación previsto en sus artículos 115 a 120 (Sentencia de 15 de enero de 1976, Ar. 207). 


\section{DERECHOS Y TASAS: APERTURA DE ZANJAS}

Considerando: Que, a la vista de los términos en que se planteó la presente apelación, la problemática litigiosa, que la misma implica, se circunscribe a enjuiciar y resolver dos clases de cuestiones: A) La determinación del alcance y contenido del artículo 448 de la Ley de Régimen local, con objeto de precisar, si los derechos y tasas por aprovechamientos especiales, constituidos en el suelo, subsuelo o vuelo de la vía pública en favor de Empresas o explotadores de servicios que afectan a la generalidad del vecindario de un término municipal, en la hipótesis de revestir la forma de participación del Ayuntamiento en los ingresos brutos o en el producto neto de la explotación dentro de dicho término, comprende todos y cada uno de los aprovechamientos especiales que estereotipa y contempla el artículo 444 del citado cuerpo legal-tesis de "Fuerzas Eléctricas del Noroeste de España, Sociedad Anónima” y de la sentencia apelada-, o, por el contrario, el mencionado artículo 448 sólo se refiere a los aprovechamientos especiales de carácter permanente, concretamente los que se especifican en los apartados $60^{\circ}, 11,13,20$ y 25 de aquel artículo, sin comprender aquellos otros no permanentes, entre los que estarian los de los apartados 7.॰, 8. y 9. $\mathrm{del}$ tantas veces aludido precepto y, en especial, "la apertura de calicatas o zanjas en la vía pública o terrenos del común, y en general cualquier remoción del pavimento o aceras en la vía pública"-postura de las representaciones de la Administración y del Ayuntamiento de La Coruña-. B). Si en el supuesto de ser anulables las liquidaciones controvertidas, la referida anulación puede llevarse a cabo sin la previa o simultánea de la Ordenanza amparadora y causante de las referidas liquidaciones. (Sentencia de 25 de febrero de 1976, Aranzadi 843).

De estas dos cuestiones, el Tribunal Supremo resuelve la primera en favor de la empresa eléctrica; y la segunda la resuelve en el sentido de que la declaración de nulidad de las liquidaciones practicadas se dispone por cuanto se oponen a lo establecido en la Ley, sin necesidad de anular la Ordenanza que no fue impugnada a su tiempo.

\section{Diputaciones RECAUdADORAS DE CONTRIBUCIONES DEL ESTADO}

Considerando: Que la pretensión de no constituir depósito alguno, por los valores perjudicados incursos en segundo grado de responsabilidad, y de que se cancelen los ya constituidos, se apoya en el artículo 661-4 de la Ley de Régimen local, que exceptúa a las Corporaciones locales de la constitución de cauciones, fianzas o depósitos ante Tri- 
bunales de cualquier jurisdicción u organismos de la Administración; precepto que constituye, por el marco sistemático en que se inserta, una medida más de protección para las Haciendas locales, lo que en modo alguno puede significar que la Ley haya tratado de fortalecer la posición de tales Haciendas, en detrimento de la estatal, pues bien expresivos son los apartados primero y último del propio artículo 661, cuando admiten, que los créditos liquidados a favor de la Hacienda pública, puedan exigirse a las Corporaciones locales por el procedimiento de apremio, en la forma determinada en el Estatuto de Recaudación, y que la acción inspectora se efectúe con sujeción a las disposiciones especiales sobre la materia; y es lógico que así sea, pues si protección merecen las Haciendas locales, mayor es la que debe dispensarse a la Hacienda del Estado, por lo que la preeminencia de ésta frente a la de las Diputaciones, justifica que las últimas tengan que prestar fianza para encargarse de la gestión recaudatoria, si bien, la Ley de 11 de abril de 1942 permite en su artículo $2 .^{\circ}$ que se efectúen como fianza todos o parte de los recursos provinciales cuya exacción corre a cargo de la Hacienda; siendo de advertir, que la mencionada Ley de 1942, con la constitución de fianza en ella exigida de modo implícito, subsiste en su integridad después de la posterior Ley de Régimen local, cuyo artículo 271 determina que las condiciones del servicio de recaudación de las contribuciones del Estado, serán fijadas por el Ministerio de Hacienda, conforme a la legislación aplicable, la cual, en consecuencia, por su especialidad, no puede verse afectada por el contenido del artículo 661-4 de aquella Ley, aparte del carácter voluntario que para las Diputaciones tiene la prestación del servicio de que se trata, y de la posibilidad de repercutir, que se les reconoce, frente a los recaudadores de zona. (Sentencia de 29 de enero de 1976, Aranzadi 495).

\section{JURISDICCION CONTENCIOSO-ADMINISTRATIVA}

No EXIGENCIA DEL PREVIO PAGo DE EXaCciones locales PARA ACUDIR A LA VÍA CONTENCIOSA

No se exige por ley tal previo pago; antes al contrario, dispensa de su cumplimiento el artículo 727, 4, de la Ley de Régimen local y el artículo 238, 2, del Reglamento de Haciendas locales y el 323 del Reglamento de Organización, Funcionamiento y Régimen jurídico de las Corporaciones locales.

\section{Dice al efecto el Tribunal Supremo:}

Que por la parte codemandada se aduce en su contestación la inadmisibilidad del presente recurso con base en la alegación de que la 
parte recurrente, al interponerlo, no había hecho efectivo el importe de la liquidación impugnada, sino que se limitó a aportar un aval bancario; mas tal motivo de inadmisibilidad no puede ser acogido, ya que, poniendo en relación el artículo 52-2-e) con 132-4 ambos de la Ley jurisdiccional, y el último de ellos según la redacción que le fue dada por la Ley 10/1973, se llega a la lógica conclusión de que el aludido requisito del previo pago a que se refiere el primero de dichos preceptos sólo es exigible en los casos en que proceda con arreglo a otra ley distinta de la jurisdiccional y reguladora de la materia de que se trate, como con reiteración lo viene proclamando reciente jurisprudencia - sentencias de 14, 27 y 30 de junio, y 6 de julio de 1973-; y, en materia de haciendas y exacciones locales está claro que la normativa aplicable no solamente no exige el requisito en cuestión, sino que, por el contrario, dispensa de su cumplimiento, según se infiere de los artículos 727-4 de la Ley de Régimen local, 239-2 del Reglamento de Haciendas locales y 323 del Reglamento de Organización, Funcionamiento y Régimen jurídico de las Corporaciones locales. (Sentencia de 2 de febrero de 1976, Ar. 361).

\section{MONUMENTOS HISTORICO-ARTISTICOS}

\section{AUDIENCIA DE LOS INTERESADOS EN EL EXPEDIENTE}

CoNSIDERANDo: Que examinadas las escasas diligencias que se califican de expedientes - compuesto de 11 folios y cinco tarjetas postales-se aprecia que, aparte la solicitud del Ayuntamiento de Ribadeo de que se declare "paisaje pintoresco la Ría", sólo contiene un informe del Comisario General, a solicitud del Director General de Bellas Artes para declaración de Conjunto Histórico-Artístico y Paisaje Pintoresco la Villa y Ría de Ribadeo y otro del Servicio de Información Artística Arqueológico o Etnológico del Distrito Universitario de Santiago de Compostela y un croquis que, sin fijarse en el casco urbano, no determina la zona o zonas afectadas por la decisión, lo que unido a las cinco postales, integran el esencial contenido del diligenciado. De todo ello no aparece la tramitación ordenada y completa que señalan las disposiciones de la vigente Ley de Procedimiento administrativo, no sólo en vista de las reglas de economía, celeridad y eficacia que animan la actividad administrativa sino para salvar el "status jurídico" del administrado, que como declara su exposición de motivos es uno de los fines del procedimiento, por lo que, cuando los interesados o afectados por una decisión administrativa no han sido convocados, o citados para defenderse, la legitimidad de tales diligencias o expedientes adolecen de un defecto tan notorio que tienen que ser subsanados, para que los derechos afectados no se vean vulnerados, sin posibilidad de defensa y la justicia sea cumplìda. 
CONSIDERANDO: Que, consecuentemente, al no aparecer que hayan sido convocados, tanto el Ayuntamiento de Ribadeo como los vecinos e interesados en el expediente para ser oídos y defenderse, si lo estiman procedente, así como las asociaciones intermedias que reúnan condiciones de legitimación para comparecer, por afectarles la pretendida declaración de Conjunto Histórico-Artístico tanto de la Villa como de la Ría. (Sentencia de 4 de febrero de 1976, Ar. 591).

\section{POLICIA MUNICIPAL}

\section{Circulación urbana: estacionamiento de autobuses} DE CONCESIONARIO DE SERVICIO REGULAR DE TRANSPORTE POR CARRETERA

La tesis del recurrente, centrada en un supuesto derecho de estacionar sus autobuses de servicio regular interurbano en cualquier parte de la vía pública, carente de concreta prohibición pugna con el artículo 10, párrafo 12, apartado d), del Reglamento de 9 de diciembre de 1949 sobre Ordenación de Transportes por Carretera, precepto que el apelante invoca en el sentido de estimar que indirectamente le confiere facultades como concesionario para constituir en garaje de sus autobuses las calles de la ciudad, pero las previsiones que en la referida norma se exigen al concesionario versan sobre organización de los servicios en materia de la específica clase de transportes que aquel Reglamento regula desarrollando la Ley de 27 de diciembre de 1947, por lo cual, la apuntada norma sólo genéricamente habla de servicios de estacionamiento y entretenimiento del material móvil, sin interferir, antes bien, con claro propósito de coordinación, el distinto ámbito ordenador del tráfico urbano legalmente confiado a la tutela de la autoridad municipal, en cuya virtud, y sobre la aceptada base de no apreciarse discordancia alguna entre dicha legalidad y el artículo 11 de las Ordenanzas Especiales de Circulación del Ayuntamiento de Zaragoza, la carencia de expresa cita de garajes entre las previsiones exigidas por el examinado precepto del Reglamento de 1949 resulta ineficiente para desvanecer la tipicidad de las infracciones administrativas a que estos autos se contraen. (Sentencia de 22 de enero de 1976, Ar. 568).

\section{LICENCIA DE OBRAS: CONSTRUCCIÓN DE LOCAL COMERCIAL, CON ESCAPARATE, EN EL PORTAL DE ENTRADA A LA CASA}

Considerando: Que, en cuanto a la construcción de local comercial, con escaparate, en el portal de entrada a la casa, como constan en el mismo expediente (pieza número 3 bis, folios 2 a 9 , y pieza 2, folio 21) las dos licencias de apertura de establecimiento a nombre de los arren- 
datarios ocupantes don José B., de fecha 31 de marzo de 1960, y doña Concepción C., de fecha 22 de mayo de 1963, cuyos otorgamientos necesitaron ineludiblemente la previa de obras, así como informe favorable del Arquitecto municipal, en relación con las normas urbanísticas, según los artículos $70^{\circ}$ y $8 .^{\circ}$ del Reglamento de la concesión de licencias de aperturas de establecimientos, de 1 de junio de 1940, no hay la más mínima duda en afirmar que ya antes había otorgado el Ayuntamiento la licencia de obras; y si aparece infringido el artículo 72-4 de las Ordenanzas Municipales de Edificación, por tratarse de local comercial situado en portal de acceso a la casa, ello podrá ser materia de errónea concesión para cuyo remedio existen otros cauces legales, muy distintos al ahora utilizado; imponiéndose mientras tanto el más absoluto respeto a la seguridad jurídica y a los derechos de los particulares. (Sentencia de 23 de enero de 1976, Ar. 643).

\section{LICENCIA: COMPETENCIA DE LA CORPORACIÓN MUNICIPAL}

Considerando: Que la nueva alegación de la parte apelante pretendiendo atribuir a la Cédula de Calificación Definitiva expedida por el Instituto Nacional de la Vivienda valor probatorio de que la construcción se ha ajustado al Proyecto no puede admitirse en términos tan absolutos que vincule a la Corporación municipal, otorgante de la licencia, ya que ambos Organismos se mueven dentro de diferentes ámbitos de competencia. Al Ministerio de la Vivienda y a los Organismos dependientes de él corresponde efectivamente la comprobación de que lo construído se ajusta al Proyecto en cuanto esta adaptación influya en la clasificación de las viviendas y su adscripción al régimen de bonificaciones previsto en la Ley, pero en modo alguno esta competencia de los órganos de la Vivienda pueden cercenar la que corresponde a los órganos municipales por virtud de los artículos 165 y 171 de la Ley sobre Régimen del Suelo y Ordenación Urbana y concordantes del Reglamento de Servicios de las Entidades locales, en orden a la concesión de licencias, así como a la suspensión o demolición de obras no ajustadas a las condiciones impuestas en aquéllas, facultades que a estos órganos locales competen en exclusiva en el desarrollo de su actuación urbanística. (Sentencia de 4 de febrero de 1976, Ar. 752).

\section{LICENCIA: CARÁCTER REGLADO}

Considerando: Que es doctrina general la que sostiene que el acto licencia, de acuerdo con su naturaleza, postula inmanentemente una obligada adecuación a la norma, no sólo como presupuesto existencial sino incluso, de lícita vigencia, en base de lo cual la jurisprudencia ha declarado reiteradamente (sentencias de 23 de junio de 1971, 13 de di- 
ciembre de 1973, 16 de enero, 26 de junio y 24 de octubre de 1974, etc.) el carácter reglado de esta actividad municipal que propiamente consiste en conceder o denegar la licencia pedida, según que lo instado se acomode o aparte de la solución of recida por las normas legales o reglamentarias aplicables, ya que éstas son preceptos terminantemente encauzadores de sus facultades dentro de cuyos límites ha de resolverse, deviniendo, en consecuencia, obligada la concesión cuando la petición del particular reúna los requisitos objetivos exigidos, en cuanto adecuada a ley de ordenanza; y al contrario, cuando no se cumplan tales exigencias la autoridad municipal no puede por acto particular infringir lo establecido por vía general, ni tampoco ampliar o modificar la titularidad o impropiamente la capacidad jurídica del solicitante, ya que ésta no puede ser afectada por un acto de intervención que por su naturaleza ha de limitarse a velar por que el derecho ya existente se acomode en su ejercicio a las disposiciones que lo predeterminan en razón o juego del interés público. (Sentencia de 15 de enero de 1976, Aranzadi 476).

\section{LICENCIA: SILENCIO ADMINISTRATIVO POSITIVO}

La jurisprudencia viene declarando a través de numerosas sentencias de este Tribunal, tales las de 31 de octubre de 1963, 27 de mayo de 1967, 19 de diciembre de 1970 y otras muchas en relación con los efectos del silencio administrativo positivo, que para que se produzca su efecto en relación con las licencias municipales es preciso la tangibilidad de un derecho preexistente en el patrimonio del autorizado que clame por la posibilidad de su ejercicio y por la eliminación de las cortapisas legales que impidan su eficacia práctica, pero sin que su existencia implique que pueda concederse tácitamente lo que de modo expreso y si se hubiere examinado no hubiera podido ser otorgado, doctrina, ésta, que resulta debe ser aplicada con toda su amplitud y de manera especial, cuando venga referida a licencias que cual sucede en el caso de autos son para apertura de establecimientos dedicados a actividades incluidas en el ámbito de las reguladas por el Reglamento de Actividades Molestas, Insalubres, Nocivas y Peligrosas. (Sentencia de 14 de noviembre de 1975, Ar. 190 de 1976).

\section{LICENCIA: MURO DE CIERRE}

Es obligado obtener la licencia municipal al efecto, de acuerdo con lo dispuesto en el artículo 165 de la Ley del Suelo. (Sentencia de 31 de diciembre de 1975, Ar. 330 de 1976). 


\section{RUINA: UNIDAD PREDIAL}

ConsIDERAndo: Que una reiterada jurisprudencia del Tribunal Supremo tiene establecido el concepto de aunidad predial», de modo que la declaración de ruina ha de venir referida a la totalidad de la construcción y no a partes determinadas de la misma, no obstante lo cual ha matizado el supuesto excepcional, para el que da pie al artículo 170 , número 1, de la Ley del Suelo al decir: "Cuando alguna construcción o parte de ella estuviere en estado ruinoso...n de que se trate de construcciones aisladas e independientes, que formen cuerpos separados, en cuya hipótesis admite la ruina limitada a tales cuerpos de construcción, y así este supuesto excepcional aparece formulado entre las más recientes sentencias del Alto Tribunal, en la de 8 de mayo de 1974, en estos expresivos términos "para que pueda hablarse de ruina parcial, hemos de estar en presencia de cuerpos independientes que permitan una normal segregación de cada uno de ellos» de forma tal que, como establece la sentencia de 23 de marzo de 1974, tales cuerpos separados sean susceptibles de ser utilizados de forma autónoma normalmente sin que la ruina de los mismos arrastre la de los demás. (Sentencia de 9 de diciembre de 1975, Ar. 194 de 1976).

\section{PROCEDIMIENTO ADMINISTRATIVO}

Notificaciones: competencia del SeCRetario de la CoRporación

Considerando: Que del estudio de las actuaciones administrativas se desprende que las afirmaciones y circunstancias recogidas como fundamento de la concesión de la oficina de farmacia a doña Rosa María de la M. G. en la calle de Marqueses de Llupia, Urbanización Segur en Calafell (Tarragona), no gozan de la justificación debida para darlas como probadas, pues los documentos de la Alcaldía no pueden constituir las certificaciones que se pretenden presentar dada la carencia de poder certificante que estando atribuida a los Secretarios como norma general, únicamente les está atribuida a los Alcaldes cuando un precepto legal expreso se lo atribuye concretamente; así lo dispone el artículo 318 del Reglamento de Organización, Funcionamiento y Régimen jurídico de las Corporaciones locales, desarrollando y confirmando el 341 de la Ley de Régimen local, texto refundido de 24 de junio de 1955, que califica de fedatarios a los funcionarios secretariales. (Sentencia de 10 de febrero de 1976, Ar. 892). 


\section{SEGURIDAD SOCIAL AGRARIA}

\section{AYUNTAMIENTOS: CUOTA EMPRESARIAL}

Considerando: Que de conformidad a lo establecido en la citada sentencia de 6 de abril de 1974, ala cuestión de la no sujeción a la cuota empresarial de los que aun siendo sujetos pasivos de la Contribución Territorial Rústica no sean titulares de una empresa agraria está igualmente reconocida en las sentencias de 23 de marzo de 1971 (Sala Cuarta del Alto Tribunal) y por las de la Sala Tercera, de 15, 16 y 27 de diciembre de 1972 y 5 de junio de 1973, entre otras, sintetizándose la doctrina establecida en la última citada por referencia a la Ley de Seguridad Social Agraria, artículo 56, 1., en relación con el artículo $4^{\circ}$, de donde se deduce que no basta para la sujeción a la cuota empresarial la mera titularidad dominical de las fincas sujetas a la Contribución Rústica y Pecuaria, sino que se precisa la explotación de las mismas en concepto de empresario o titular de una explotación agraria, basándose también en los principios que informan nuestro Derecho tributario, por lo que no es necesario reiterar in extenso lo alli expuesto. (Sentencia de 21 de enero de 1976, Ar. 213).

En la sentencia de 9 de febrero de 1976 (Ar. 369) se dice:

Considerando: Que la fijación de cuota objeto de este pleito corresponde al ejercicio de 1967, en que era plenamente aplicable, en su redacción primitiva la Ley de Seguridad Social de 31 de mayo de 1966; por lo que, al no ser posible aplicar ahora, por falta de retroactividad expresa, las disposiciones legales y reglamentarias posteriores a la citada Ley, las que han tenido total vigencia, a los efectos que así pudieran interesar, después del ejercicio de 1971, es indudable que, en el caso presente, y sin adelantar en absoluto futuras soluciones, hay que mantener las dos premisas fundamentales que sirven de soporte al fallo apelado y que son: carácter económico-administrativo inicial de la cuestión planteada con motivo de la fijación de cuota, antes referida, por la asimilación que el artículo 46 de la Ley de 31 de mayo de 1966 hace a la Contribución Rústica y Pecuaria; y la exigencia del binomio aempresario-trabajador», para el sometimiento al pago de la cuota empresarial, que se consigna en 1966, como auténtico seguro obligatorio; todo lo cual conduce a confirmar íntegramente la sentencia objeto del presente recurso de apelación; sin que sea de apreciar temeridad ni mala fe al efecto de una especial imposición de costas. 
Y en la sentencia de 18 de diciembre de 1975 (Ar. 460 de 1976) se consigna:

Considerando: Que al mantenerse en la sentencia recurrida el reiterado criterio sentado por esta Sala en relación cor las dos principales cuestiones litigiosas -competencia de los Tribunales Económicoadministrativos para conocer de las reclamaciones sobre las cuotas empresariales del Régimen Especial Agrario de la Seguridad Social y no sujeción a dichas cuotas de quienes auri siendo sujetos pasivos de la Contribución Territorial Rústica y Pecuaria no sean titulares de una empresa agraria-, criterio proclamado, entre otras muchas, en las sentencias de 28 de abril, 16 y 21 de mayo, 24 de junio y 7 de noviembre de 1975, es procedente, con la desestimación de los recursos de apelación interpuestos, la confirmación de la sentencia apelada en los mencionados particulares; siendo importante dejar constancia de que las aludidas sentencias de este Tribunal han propugnado la aplicación del expresado criterio en orden a ambas cuestiones, en relación con el ejercicio de 1971 - que es el de que aquí se trata-, por ser para el mismo plenamente de referencia en su redacción primitiva la Ley de la Seguridad Social Agraria de 31 de mayo de 1966, y al no ser posible tener en cuenta al respecto, por falta de retroactividad expresa, las disposiciones legales y reglamentarias posteriores a la citada Ley que precisamente han tenido su total vigencia, a los efectos que ahora interesan, después de dicho ejercicio, conforme a los razonamientos expuestos en el considerando segundo de la reciente sentencia de 26 del pasado mes de noviembre.

\section{SOLARES E INMUEBLES DE EDIFICACION FORZOSA}

\section{TARDANZA DE LA RESOLUCIÓN MUNICIPAL}

Considerando: Que también esta Sala, en sentencia de 23 de septiembre de 1969, rechazó la posibilidad de interpretar el artículo 15, número $1 .^{\circ}$, apartado e), del Reglamento de Edificación Forzosa en el sentido propugnado por los apelantes, quienes sostienen que el no pronunciamiento de la resolución dentro de los seis meses desde que se incoó el expediente produce de modo automático la subrogación en estas funciones del organismo urbanístico competente, según previene el artículo $8 .^{\circ}$, número $2 .^{\circ}$, del mismo Reglamento, con aunada pérdida de la competencia municipal para resolver el caso, lo que determinaría, según esta tesis, invalidez del acuerdo extemporáneo que, en el actual supuesto, ordenó incluir la finca en el Registro; interpretación, la así expuesta, que ya la sentencia aludida declaró improcedente, pues tanto una exégesis gramatical de los preceptos mencionados, como su sistemática conexión con los artículos $5 .^{\circ}$ y 206 de la Ley del Suelo, a los 
que reenvía el $8 .^{\circ}$ del Reglamento susodicho, y su relación también con los 15, número 2, de éste; 49 y 61 de la Ley de Procedimiento administrativo, y 293 de la de Organización, Funcionamiento y Régimen juridico de las Corporaciones locales, vedan atribuir a la cuestionada subrogación un carácter automático que ni explícitamente resulta de los preceptos reglamentarios que la parte invoca, ni que tampoco es dable inferir de su finalidad, teniendo en cuenta las contradicciones que resultarian con las demás citadas normas y principios que las inspiran, entre los que destaca como fundamental para la materia examinada el de condicionar a la decisión de organismo superior el traspaso de funciones urbanísticas de los Ayuntamientos que actuasen en general con notoria negligencia, directriz ésta que, establecida en el artículo 206 de la Ley del Suelo, y también informante del 15, número 3, del Reglamento de 1964, impide prescindir del susodicho acuerdo superior, para la efectividad de la subrogación aludida, sin otra base que la de tratarse aquí de morosidad en resolver dentro del concreto ámbito de un expediente y no de la genérica actuación municipal en este orden, pues precisamente es a la normativa general sobre la subrogación a lo que remite el artículo 15 , número 1 , apartado e), del $\mathrm{Re}$ glamento, y ninguna razón existe para escindir el contenido de aquella normativa y condiciones que impone a la subrogación, suprimiendo arbitrariamente la del previo acuerdo de órgano urbanístico superior, que así se configura como presupuesto del traspaso de funciones también para el concreto caso de demora en la resolución del expediente, lo que a la par que excluye la subrogación automática alegada por los apelantes, priva de significación en este aspecto a la solicitud dirigida por uno de los arrendatarios a la Gerencia Municipal de Urbanismo para que declarase caducado el proceso administrativo, pues, conforme a lo expuesto, no era ése el cauce para promover el superior acuerdo de subrogación a que se ha hecho referencia. (Sentencia de 22 de diciembre de 1975, Ar. 326 de 1976).

\section{URBANISMO}

\section{LiCENCIA ERRÓNEAMENTE OTORGADA}

Considerando: Que comprobado el otorgamiento erróneo de la licencia, puesto que se basó en el inexacto conocimiento de una realidad objetiva, cual es la calificación de la "parcela", y por este error se aplicó el régimen correspondiente a la zona urbana semiintensiva, debió la Administración, tal como dice el artículo 172, número 1, de la Ley sobre Régimen del Suelo y Ordenación Urbana, anular la licencia y disponer lo que previene el artículo 171 respecto a la demolición de las obras no susceptibles de legalización, y, además, determinar, tal como dice el artículo 172, número 2, para el caso de otorgamiento erróneo, la indemnización de los daños causados al titular de la licen- 
cia y que, por tanto, no sean consecuencia de acto a él imputable; conclusión que debe llevarnos a la estimación del recurso en los términos expresados. (Sentencia de 13 de diciembre de 1975, Ar. 260 de 1976).

\section{Plan definitivamente aprobado: Rectificación DEl acto admi- NISTRATIVO ALEGANDO ERROR DE HECHO}

CONSIDERANDo: Que toda la cuestión, acertadamente resuelta por la Sala en Primera Instancia, se centra en si la resolución de la Comisión Provincial de Urbanismo recurrida, al dejar sin efecto la antes dictada por el mismo órgano aprobando el Plan Parcial de Ordenación de la finca "Cavaleri», se limitó a rectificar el error de hecho padecido en ésta en cuanto al carácter rústico de los terrenos que se pretendía urbanizar; en relación con lo cual es de tener en cuenta que el artículo 111 de la Ley de Procedimiento administrativo invocado no encierra una nueva posibilidad de revisión de oficio de los actos administrativos, aparte las proporcionadas por los artículos 109 y 110, sino una potestad de alcance mucho más limitado en cuanto sólo arbitra una fórmula para evitar que simples errores patentes pervivan y produzcan efectos desorbitados o necesiten para ser eliminados de la solemnidad de un procedimiento de revisión; mas por eso mismo esa posibilidad de rectificación de pleno debe ceñirse a los casos en que el propio actor revele una equivocación evidente por sí misma y manifiesta en el contenido del acto susceptible de rectificarse sin eliminar aquél, pero en modo alguno permitir una revocación de oficio que, de proceder, debe seguir otros cauces; y que ha sido lo que aquí pretendía la Administración, puesto que, en efecto, anuló el anterior acto aprobatorio del Plan, entendiéndolo erróneo al haberse referido a terrenos rústicos, por considerar que éstos no son susceptibles de ordenación a falta de Plan General, razonamiento que por sí mismo revela que no se trataba de rectificar un mero hecho erróneo en el contenido de aquella resolución, sino de revocarla como consecuencia de una apreciación errónea de los hechos, es decir, de un error en la aplicación del Derecho por equivocado entendimiento de los presupuestos de hecho, lo que es bien diferente $y$. por supuesto ajeno al contenido del artículo 111 invocado. (Sentencia de 13 de febrero de 1976, Ar. 1.088).

\section{PlanES: MODIFICACIÓN DE LOS MISMOS: APROBACIÓN DEFINITIVA}

CONSIDERANDo: Que aunque en el tema polémico de la naturaleza de los actos de aprobación definitiva de los Planes de Ordenación Urbana objeto de aprobación provisional por las Corporaciones locales, resuelto con soluciones no siempre coincidentes, aceptemos la tesis de que son actos de control o fiscalización e incluso con individualidad jurídica propia, que proporciona eficacia al acto fiscalizado, tesis que 
encuentra hoy un argumento decisivo en el texto del artículo 225 de la Ley del Suelo, según la reforma de la Ley 19 de 1975, pues ha de entenderse que remite, en cuanto al régimen de impugnación, al número $2 .^{\circ}$ del artículo 29 de la Ley de esta Jurisdicción, lo que significa un pronunciamiento legislativo sobre la naturaleza de tales actos, en una línea que ya fue sostenida por este Tribunal Supremo, tal como se recoge, entre otras, en la sentencia de 28 de diciembre de 1970, no se sigue de tal calificación que el órgano al que está atribuida la competencia para la aprobación definitiva se le niegue el control de la legalidad del Plan o de su modificación, pues en el cuadro de los poderes de control o fiscalización cabe que la Ley otorgue, a través de la técnica de la aprobación, el velar porque la actividad del Ente municipal respete la legalidad urbanística y se desarrolle dentro del cauce jurídico establecido en el derecho aplicable, y éste es, justamente, el alcance que a la competencia del órgano de aprobación definitiva asigna el artículo 32, apartado 2, de la Ley del Suelo cuando dispone que a tal órgano compete examinar "en todos sus aspectos" el Plan, tesis, por lo demás, que, aun con matices sobre la naturaleza del acto de aprobación definitiva, es la que, en una línea jurisprudencial uniforme, se ha mantenido por este Tribunal Supremo, como se infiere de lo que dijimos en las sentencias de 8 de junio de 1961, 25 de marzo de 1966, 29 de octubre de 1967, 26 de febrero de 1970, 29 de enero de 1971, 26 de junio y 2 de diciembre de 1974, 2 y 17 de abril de 1975. (Sentencia de 22 de enero de 1976, Ar. 566).

\section{ORdENACIÓN DE MANZANAS}

Considerando: En cuanto al fondo de la cuestión objeto de la presente litis, que las llamadas ordenaciones de manzanas, término éste que, por cierto, según ha expuesto esta misma Sala en diversas sentencias, no está expresamente reconocido por el moderno Ordenamiento jurídico urbanístico, aunque lo esté en algunas Ordenanzas municipales, cual sucede con las de Zaragoza del año 1939 (anteriores a la Ley del Suelo), pueden tener una doble finalidad, bien ejecutar un Plan de Ordenación preexistente; bien constituir un Plan autónomo, referido a una porción superficial más o menos grande, delimitada por la confluencia de diversas vías públicas; que puede presentarse como nuevo (si opera sobre sectores anteriormente no urbanizados), o como modificación de una planificación anterior ( $\mathrm{si}$ actúa sobre sectores previamente urbanizados).

Considerando: Que cuando tales ordenaciones de manzanas se presentan como ejecución de un previo Plan de Ordenación urbana, es necesario que éste haya sido aprobado en forma, debiendo ajustarse aquéllas a los estrictos límites de éste, por exigirlo un elemental deber de disciplina urbanística. 
Considerando: Que cuando las ordenaciones de manzanas se presentan como pequeños Planes urbanísticos, con carácter autónomo, referidos a la superficie de terreno existente entre la confluencia de varios viales, ya operen sobre terrenos no urbanizados, ya sobre otros que lo estuvieren anteriormente, requieren, en todo caso, el sometimiento a unas normas procedimentales que están contenidas, según sea el caso, en el artículo 32 ó en el 39 de la Ley del Suelo, a través de las cuales pueda contrastarse su legalidad y se garanticen los derechos no sólo de los directamente interesados en el mismo, sino de toda la comunidad a la que, según se expuso más arriba, la Ley le concedió la posibilidad de una fiscalización directa, a través de la acción pública perfilada en el artículo 223 de la Ley del Suelo; pues no debe olvidarse que esos Planes, no por reducidos en su superficie, son menos trascendentes en la problemática urbanística, ya que a través de ellos podría fácilmente incidirse en un desquiciamiento que hiciera imposible una posterior acción ordenadora de conjunto. (Sentencia de 6 de febrero de 1976, Ar. 812).

Nemesio Rodrfguez Moro 